\title{
Dificuldades e Perspectivas dos Estudantes de Ciências Contábeis da Universidade Federal do Paraná Segundo o Perfil Socioeducacional
}

\begin{abstract}
Resumo
Este estudo tem como foco principal compreender os aspectos existenciais precedentes ao ingresso na universidade e se dá pelo delineamento do perfil socioeducacional dos estudantes do curso de Ciências Contábeis da Universidade Federal do Paraná (UFPR). Para alcançar tal intento, executa-se um estudo acerca dos aspectos inerentes à formação e à definição profissional exigidas pelo mercado de trabalho, permeadas pela ênfase nas dificuldades percebidas, decorrentes da formação socioeducacional do estudante. De forma complementar a esta pesquisa, investigam-se as aspirações profissionais do estudante, delineadas em conjunto com o perfil socioeducacional, durante sua formação como indivíduo, e a manutenção, ou não, dessas perspectivas durante o período da universidade. Trata-se de estudo descritivo, por meio de levantamento e auxílio da estatística descritiva, $\chi^{2}$ (qui-quadrado), Análise de Clusters e Análise Discriminante, que identificou a existência de dois grupos com perfis distintos entre os estudantes de Ciências Contábeis nas turmas investigadas. Esses grupos foram denominados “Grupo Ascensão", uma vez que esses estudantes reúnem aspectos dos estratos sociais inferiores; e Grupo Manutenção, que reúne características dos estratos sociais com características mais elevados. As evidências a que chegou o estudo permitem concluir que os grupos têm dificuldades percebidas e perspectivas profissionais distintas entre si.
\end{abstract}

Palavras-chave: Estudante de Ciências Contábeis; Ensino de Contabilidade; Perfil socioeducacional; Dificuldades percebidas; Perspectivas profissionais.

\begin{abstract}
Laurindo Panucci-Filho
Mestre em Contabilidade (UFPR), Professor Assistente da UENP - Universidade Estadual do Norte do Paraná. Contato: Rodovia PR 160 Km 0 ( Saída para Leópolis), Cornélio Procópio, PR, Brasil, CEP: 86300-000. E-mail: laurindopanucci@hotmail.com
\end{abstract}

\section{Ademir Clemente}

Pós-Doutor em Economia do Trabalho (University of London), Professor Adjunto da Universidade Federal do Paraná (UFPR). Contato: Av. Prefeito Lothário Meissner, 632, Jardim Botânico, Curitiba, PR, Brasil, CEP: 82010-170.

E-mail: ademir@ufpr.br

\section{Alceu Souza}

Doutor em Administração (FGV-SP), Professor da Pontifícia Universidade Católica do Paraná (PUC/PR). Contato: Rua Imaculada Conceição, 1155, Prado Velho, Curitiba, PR, Brasil, CEP: 85.555-000. E-mail: alceu.souza@pucpr.br

Marcia Maria dos Santos Bortolocci Espejo

Doutora em Controladoria e Contabilidade (USP), Professora Adjunta da Universidade Federal do Paraná (UFPR). Contato: Av. Prefeito Lothário Meissner, 3.400, Jardim Botânico, Curitiba, PR, Brasil, CEP: 82010-170. E-mail: marciabortolocci@ufpr.br 


\section{Introdução}

Um dos processos que ainda designam a seleção de novos estudantes ao ingresso na universidade é o exame vestibular. Este se caracteriza normalmente como um conjunto de provas classificatórias de aferição dos conhecimentos adquiridos nos ensinos fundamental e médio dos candidatos, sendo um dos principais meios de acesso ao ensino superior, público e privado, no Brasil. (Rehfeldt, 2006; Kurchaidt, Nascimento, Zanette \& Camargo, 2008; Stefanello, 2010).

Sua importância é maior nas instituições públicas, que, pela gratuidade, são geralmente as mais procuradas, o que constitui uma das principais barreiras de acesso ao ensino superior a muitos estudantes brasileiros, sobretudo aqueles vindos dos estratos inferiores de renda e aqueles sujeitos a adversidades como a necessidade de conciliar trabalho e estudo de baixa qualidade. Entre os motivos para isso, está o número reduzido de vagas em instituições públicas e a formação educacional do estudante nos níveis fundamental e médio, em sua grande maioria proveniente do ensino gratuito noturno. (Rehfeldt, 2006; Stefanello, 2010).

Esse contexto torna o exame vestibular um processo que procura selecionar os candidatos com maiores aptidões para concluir o ensino superior na área de formação escolhida. No panorama de entrada na universidade, além da barreira que representa o exame vestibular, fatores como a formação socioeducacional do estudante intervêm na escolha do curso superior e no desempenho durante a universidade.

De modo geral, a formação educacional e a ocupação profissional de pais e mães, juntamente com a renda da família, influenciam muito ao estudante quanto à preferência e à escolha por determinado curso superior e seu destino como profissional de nível universitário.

O perfil socioeducacional acumulado durante a formação do indivíduo, como as condições de renda da família, ocupação e nível educacional dos pais e formação educacional de base, resulta em perspectivas de transformação do modo de vida, das realizações e conquistas pessoais dos estudantes do curso superior, principalmente os de Ciências Contábeis, cientes da formação superior, em uma conquista que os diferencia da de seus pais e familiares.

Como período de trajetória na vida do estudante, o ensino superior cumpre a tarefa de transmitir conhecimento e preparar o futuro profissional para o mercado de trabalho, bem como atender à sociedade, oferecendo-lhe profissionais capazes de operar mecanismos sociais, aliando as perspectivas dos estudantes ao interesse da sociedade em transformação.

Mesmo com algumas limitações no número de vagas, no número de professores e na capacitação acadêmica, a educação superior no Brasil tem procurado, nas últimas décadas, suavizar a pluralidade ou disparidade educacional entre os indivíduos, uma vez que os problemas decorrentes dessas potencializam as diferenças econômicas e sociais. Sob esta perspectiva, a distinção entre os estudantes é latente pela formação educacional de base, pois nem todos frequentam um ensino de qualidade desejável, o que resulta em limitações para os indivíduos, tanto durante o ensino superior quanto em termos das perspectivas profissionais.

Com base nesses argumentos, esta pesquisa procura responder à seguinte questão: Como os diferentes perfis socioeducacionais influenciam nas dificuldades percebidas e nas perspectivas dos estudantes de Ciências Contábeis da UFPR?

Intrinsecamente à análise das adversidades dos indivíduos em sociedade, como limitadoras e potencializadoras em geral, a pesquisa investiga se há formação de grupos distintos com diferentes perfis socioeducacionais, dificuldades percebidas e perspectivas profissionais entre os estudantes de Ciências Contábeis na UFPR. Seus objetivos específicos são (1) delinear os perfis socioeducacionais dos estudantes; (2) compor o quadro das principais dificuldades percebidas pelos estudantes; (3) levantar as perspectivas profissionais dos estudantes; (4) investigar estatisticamente se os perfis socioeducacionais influenciam as dificuldades percebidas; (5) investigar estatisticamente se os perfis socioeducacionais influenciam as perspectivas profissionais. 


\section{Referencial teórico}

\subsection{Aspectos socioeducacionais dos estudantes de Contabilidade}

A sociedade exerce influências sobre os indivíduos em diversos aspectos. Entre eles, estão as perspectivas de melhoria nas condições gerais de vida, sujeitas ao contexto em que estão inseridos, e os agrupamentos sociais, que são formas de compreender a organização e a estrutura social às quais os indivíduos estão submetidos, opcionalmente ou não (Guareschi, 1992; Oliveira, 1999; Ferreira, 2003; Giddens, 2005).

O conceito de estrato social e classe social surgiu como meio de compreender a organização social dos indivíduos, o comportamento com integrantes do seu grupo e de outros grupos, bem como as perspectivas particulares e individuais (Guareschi, 1992; Oliveira, 1999; Ferreira, 2003; Giddens, 2005).

Estrato social é um referencial utilizado para descrever as igualdades ou desigualdades existentes entre os indivíduos e os grupos nas sociedades humanas. Sobre isso, Giddens (2005, p. 234) argumenta: "é comum pensarmos na estratificação em termos de bens ou de propriedade, mas sua ocorrência também pode se dar com base em outros atributos, como gênero, idade, afiliação religiosa ou posto militar". Quanto ao conceito de classes, a compreensão do fenômeno social que envolve os indivíduos em grupos sociais depende da classificação e ordenação dos elementos em estudo.

Ferreira (2003, p. 122) e Oliveira (1999, p. 71) mencionam os tipos de estratificação usualmente utilizados, os quais compreendem três dimensões:

a) estratificação econômica - baseada na posse de bens materiais, resultando em uma sociedade dividida em pessoas ricas, pessoas pobres e pessoas em uma situação intermediária;

b) estratificação política - baseada na situação de mando da sociedade, de grupos que detêm o poder de condução política da sociedade;

c) estratificação profissional - baseada nos diferentes graus de importância atribuídos a cada profissão pela sociedade.

O sistema de estratos compõe-se de "indivíduos ocupando uma posição relativamente similar sob algumas características objetivas (renda, ocupação, lazer)", e a característica da estratificação "é a presença de status baseado no poder econômico, político, cultural e estilos de vida peculiares" (Rabello, 1979, p. 28). Os tipos de estratos sociais levam os indivíduos de uma sociedade a compor classes sociais em que "a posse de riquezas, juntamente com a profissão, são as bases principais das diferenças de classes" (Giddens, 2005, p. 234).

Guareschi (1992, p. 32) referencia que "a classe vai ser uma dentre as muitas maneiras de as pessoas poderem identificar subjetivamente sua posição social dentro de sociedades desiguais". Classe é a ordenação de prioridades em um sistema de estratificação dentre as várias dimensões do sistema, como renda, riqueza, status, laços de amizade, etc. (Rabello, 1979; Guareschi, 1992; Oliveira, 1999; Ferreira, 2003; Giddens, 2005).

Segundo Guareschi (1992, p. 34), os critérios mais comuns de divisão dos indivíduos em classes sociais se dão por meio de "renda e status social":

a) renda é o poder econômico de um indivíduo, geralmente medido pelo que recebe em troca do seu trabalho ou de suas posses;

b) status social refere-se ao prestígio de uma pessoa em uma sociedade e provém principalmente de sua formação educacional (escolaridade) ou sua profissão, incluindo, muitas vezes, sua importância política.

Porém, as classes são mecanismos que permitem compreender como o processo de estratificação se dá nas sociedades e, não, como forma de separar os indivíduos dentro de cada classe. A partir dos ele- 
mentos estruturais da estratificação e das classes, o conjunto de critérios que formam a sociedade pode ser mais bem compreendido e analisado sob os diversos focos de influências e perspectivas que operam em uma sociedade.

\subsubsection{O contexto socioeducacional do ingressante no curso de Contabilidade}

Em face das características voltadas para a área de negócios, do avanço científico e tecnológico nos meios de produção e de informação, do acentuado número de estudantes do sexo feminino ingressando no curso, da adequação das práticas contábeis às normas internacionais e demais preocupações com os reflexos globais sobre a profissão de contador, vêm ocorrendo mudanças nas perspectivas desse público, destacando-os dentre os demais estudantes do curso superior brasileiro (Takakura, 1992; Marion, 1999; Escerdo \& Quintana, 2007).

Parte deles conhece algumas atividades ligadas à profissão antes do ingresso no curso superior, por meio do mercado de trabalho e da formação de técnico em contabilidade, alternando seu tempo entre estudo, trabalho e lazer. Todos reconhecem a amplitude de atuação do contador, porém poucos estudantes têm claramente definido quais funções querem desempenhar no momento de atuarem no mercado de trabalho (Marion, 1999).

Parte dessa indefinição é decorrente da influência adquirida na formação técnica profissionalizante e da prematura entrada no mercado de trabalho. Sobre esse cenário, Takakura (1992, p. 21) relata que "a família, a comunidade, o sistema social, político e econômico, a cultura, o sistema educacional, os órgãos de classe, etc." influenciam na escolha do curso, nas perspectivas durante o curso e como egresso no mercado de trabalho.

Algumas circunstâncias caracterizam o contexto geral do estudante de contabilidade, as quais se alternam entre a falta de clareza quanto à definição profissional e as dificuldades enfrentadas durante o curso superior. Elas são citadas por Takakura (1992, p. 18): “a) o fato de a maioria ter feito o $1^{\circ}$ e o $2^{\circ}$ graus em escola pública e no período noturno; b) o exercício de atividade remunerada; c) dependência do trabalho para continuar os estudos; d) ausência do hábito de leitura", aspectos que revelam o perfil de um estudante trabalhador, que ajuda a família financeiramente e ingressa muito cedo no mercado de trabalho, assumindo responsabilidades múltiplas: a de contribuir para o sustento da família e manter-se como estudante. A ausência do hábito da leitura, proveniente da formação básica, e a ocupação em diversas atividades ao mesmo tempo podem causar danos à formação do estudante (Takakura, 1992).

O envolvimento com outras atividades e a formação básica trazem dificuldades para o estudante do curso superior. Takakura (1992, p. 18) cita algumas dessas dificuldades: “a) falta de tempo para dedicação às disciplinas do curso; b) falta de base no curso de nível médio; c) professores desestimulantes; d) baixa qualidade do curso". Peleias, Petrucci, Garcia, Silva (2008, p. 82) também mencionam, em sua investigação com os alunos do $1^{\circ}$ ano de Ciências Contábeis, que os alunos frequentemente têm "dificuldades financeiras, cansaço, dificuldades com as disciplinas contábeis, entre outras", além de sublinhar que "o estudo noturno é a opção possível para muitos brasileiros", situando-se entre eles os estudantes de contabilidade.

\subsubsection{Expectativas dos estudantes dos cursos de Contabilidade}

Os indivíduos, de maneira geral, movidos por perspectivas, procuram suprir necessidades elementares, em muitos casos a sobrevivência. Porém, atendida a uma necessidade fundamental, outras decorrentes surgem, redesenhando o processo de escolhas e opções. Por meio de mecanismos de distinção, conhecidos como classes e estratos sociais, os indivíduos situam-se em camadas segundo critérios.

Como elementos de transformação social, os indivíduos são os principais agentes de mudanças nas sociedades, por meio da mobilidade social que se refere ao "deslocamento de indivíduos e grupos entre 
posições socioeconômicas diferentes" (Giddens, 2005, p. 248), movimento que demanda ações, podendo ocorrer transformações em toda a sociedade. Oliveira (1999, p. 73) cita que "mobilidade social, portanto, é a mudança de posição social de uma pessoa num determinado sistema de estratificação social". Pastore (1979, p. 4) compartilha dessa afirmação, confirmando que a mobilidade social "refere-se a mudanças de status social." - status social no sentido de que cada posição social do indivíduo representa uma condição de renda, ocupação ou nível educacional.

Quanto à movimentação dos indivíduos na escala social, muitos fatores contribuem para esse evento, podendo ser resultado de ações do próprio indivíduo ou de condições que independem do seu controle (Oliveira, 1999; Giddens, 2005).

Em sentido amplo, a mobilidade social ocorre devido às desigualdades sociais em termos de direitos, privilégios, poder, obrigações e deveres na sociedade (Rabello, 1979). Ela representa, muitas vezes, a sobrevivência do indivíduo e o que ele almeja como conquistas, individualmente ou para o grupo (classe social). E, depois de alcançar uma determinada posição social, estimula-se ao acesso a níveis superiores.

A mobilidade dos indivíduos tem conotações diversas. Rabello (1979, p. 35) cita que, frequentemente, as classificações se apoiam "na riqueza, na atividade ocupacional, na educação, no parentesco, na religião e até mesmo nas características biológicas". Portanto, o estudo da mobilidade social necessita de indicadores válidos para todos os indivíduos, levando-se em conta as causas da mobilidade entre as classes (Rabello, 1979). Os indicadores usualmente adotados na compreensão da mobilidade são a atividade ocupacional, a educação e a renda (Rabello, 1979; Oliveira, 1999; Giddens, 2005).

Os indicadores de mobilidade social, quando analisados sob a ótica dos estudantes de Ciências Contábeis, revelam que estes escolheram o curso porque têm como perspectivas a estabilidade financeira e o reconhecimento pessoal e profissional, e condicionam a formação no curso de graduação a um futuro promissor - expectativas que levam em consideração a história da família e outras influências, como amigos, empresa, condições de acesso à universidade (Takakura, 1992; Leite, 2005; Escerdo, \& Quintana, 2007; Lagioia, Santiago, Gomes, \& Ribeiro, 2007; Peleias et al., 2008).

\section{Metodologia}

Esta pesquisa caracteriza-se como descritiva, pois tem como objetivo primordial descrever características de determinado fenômeno e estabelecer relações entre variáveis da pesquisa. A tipologia da pesquisa é a bibliográfica, porque abrange o referencial teórico já publicado e reúne conhecimentos em relação ao tema estudado, servindo de apoio ao levantamento da pesquisa (Gil, 1996; Cooper, \& Schindler, 2003; Richardson, 2007; Raupp \& Beuren, 2008).

Na coleta de dados, a tipologia é o levantamento, ou survey, uma vez que se pretende obter informações diretamente do grupo de pessoas que se deseja conhecer (Gil, 1996; Cooper, \& Schindler, 2003; Richardson, 2007; Raupp \& Beuren, 2008). O instrumento selecionado para este procedimento é o questionário, composto de 3 sessões. Na primeira delas, as 23 alternativas eram compostas por alternativas de múltipla escolha; na segunda e terceira sessões, eram alternativas fechadas em escala do tipo Likert de 6 pontos, sendo: (DT) Discordo Totalmente; (D) Discordo; (DP) Discordo Parcialmente; (CP) Concordo Parcialmente; (C) Concordo; (CT) Concordo Totalmente.

O questionário foi testado e validado primeiramente em uma sala do primeiro ano do curso de Ciências Contábeis da UFPR, com 40 alunos e depois, com os alunos bolsistas do programa de mestrado da UFPR. Corrigidos os equívocos constados na fase do pré-teste, foi aplicado aos alunos do segundo e terceiro anos do curso de Ciências Contábeis da UFPR, que resultou em 134 respostas válidas em 4 salas de aula - duas salas por ano de curso. A aplicação do questionário foi simultânea nas duas salas do segundo ano, em uma terça-feira, e simultânea nas duas salas de aula do terceiro ano, numa quinta-feira. Os questionários foram aplicados aos alunos que estavam em sala no dia da visita, e todos os presentes colaboraram com a pesquisa. 
O Alpha de Cronbach, testado nas 25 questões da sessão II, forneceu 0,867 de consistência interna e nas 25 questões da sessão III, forneceu 0,766 de consistência interna, resultado acima do limite inferior geralmente aceito, que é de 0,70 (Hair, Tatham, Anderson, \& Black, 2005).

A delimitação pela população intermediária do curso de Ciências Contábeis baseou-se em estudos anteriores, os quais avaliaram itens como: fatores de influência na escolha pelo curso de graduação, percepção dos estudantes do $1^{\circ}$ ano do curso de Ciências Contábeis em relação às dificuldades por eles enfrentadas no período noturno, integração na educação superior e satisfação acadêmica de estudantes ingressantes e concluintes, fatores de escolha pelo curso de Ciências Contábeis, formação e demanda do mercado de trabalho do contador (Bomtempo, 2005; Schleich, 2006; Pinheiro, 2008).

\subsection{Técnicas estatísticas de análise dos dados}

A análise e a interpretação dos dados coletados se valem da abordagem quantitativa. Richardson (2007, p. 80) cita que esta metodologia "caracteriza-se pelo emprego da quantificação tanto nas modalidades de coleta das informações quanto no tratamento delas por meio de técnicas estatísticas, desde as mais simples, como percentual, média, desvio padrão, às mais complexas, como coeficiente de correlação, análise de regressão, etc.". E ocorreu através das seguintes técnicas estatísticas: estatísticas descritivas, $\chi^{2}$ (qui-quadrado), análise discriminante e análise de clusters. O software de análise utilizado é o SPSS - Statistical Package for the Social Sciences, versão 13.

\subsection{Hipóteses}

Com base na delimitação da questão de pesquisa (Richardson, 2007), soluções tentativas são declaradas por meio de hipóteses, com o intuito de nortear o processo de pesquisa, orientar a direção do estudo, identificar fatos relevantes, sugerir a forma apropriada para o planejamento da pesquisa e fornecer uma estrutura conceitual para as conclusões resultantes (Cooper, \& Schindler, 2003).

De acordo com Gil (2009, p. 31), a hipótese "consiste em oferecer uma solução possível, mediante uma proposição, ou seja, uma expressão verbal suscetível de ser declarada verdadeira ou falsa”. É uma forma de tornar o problema de pesquisa possível de ser respondido, em meio a possíveis respostas. Cervo e Bervian (2002, p. 86) declaram que "a hipótese consiste em supor conhecida a verdade ou explicação que se busca", pois, caso o pesquisador não defina com clareza a resposta para o seu problema, a pesquisa poderá não chegar a uma conclusão adequada. Sendo assim, apresentam-se as seguintes hipóteses que serão testadas para a diferenciação entre os grupos:

$\mathbf{H}_{1}$ - Estudantes de Ciências Contábeis com diferentes perfis socioeducacionais não se diferenciam entre si quanto às dificuldades percebidas.

$\mathbf{H}_{2}$ - Estudantes de Ciências Contábeis com diferentes perfis socioeducacionais não se diferenciam entre si quanto às perspectivas profissionais.

E, como hipótese necessária para identificar a relevância de cada variável da sessão I, na formação de cada grupo, aponta-se o seguinte:

$\mathbf{H}_{0}$ - A “variável analisada" é independente e não associada à formação de cada grupo.

O resultado obtido na aplicação das técnicas estatísticas para cada "variável analisada" encontra-se na Tabela 1. 


\section{Análise dos dados}

Por meio da análise de clusters, dois grupos foram encontrados, e, utilizando-se de análise descritiva, foram identificadas características com relação a esses grupos que permitiram atribuir-lhes o nome de "Grupo Ascensão" e "Grupo Manutenção". Tais características foram confirmadas em análise de cada variável que forma o grupo. As predominantes são:

a) Grupo Ascensão - compõem este grupo indivíduos com idade na faixa de 20 a 29 anos que trabalham e contribuem com a renda familiar de até 5 salários mínimos e que estudaram o ensino médio, regular ou técnico e profissionalizante, em escola pública. Seus pais e mães possuem ensino fundamental e médio e se ocupam de atividades profissionais situadas em níveis inferiores da escala ocupacional;

b) Grupo Manutenção - neste grupo, parcela significativa dos indivíduos tem até 19 anos, trabalha e recebe ajuda financeira ou é responsável pelo próprio sustento, sendo que suas famílias possuem renda acima de 5 salários mínimos. Esses alunos estudaram o ensino médio regular predominantemente em escola particular no período diurno, e seus pais e mães possuem ensino médio e superior e se ocupam de atividades situadas em níveis superiores da escala ocupacional.

O grupo é denominado de Grupo Ascensão porque, durante a análise das variáveis, foram constatadas características que permitem evoluir para níveis superiores aos considerados como variáveis da pesquisa, tais como educação, renda e status.

O Grupo Manutenção é assim chamado porque, pela análise das variáveis, constata-se que suas características permitem que seus integrantes evoluam para níveis superiores das escalas educacionais, de renda e status, porém a tendência apresentada é de se manterem nos níveis em que se encontram atualmente. A análise descritiva das variáveis procura evidências estatísticas da contribuição de cada uma delas na formação dos grupos.

\subsection{Resumo do teste $\chi^{2}$ para as variáveis do perfil socioeducacional}

O resumo do teste $\chi^{2}$, elencado na Tabela 1 , tem como finalidade demonstrar quais variáveis influenciaram ou contribuíram significativamente para a formação de cada um dos grupos. Constatou-se que a renda $(9 ; 13)$, a ocupação $(11,12)$ e o nível educacional $(15,16)$, tal como identificou Rabello (1979), são as variáveis que mais influenciaram na formação dos Grupos Ascensão e Manutenção.

A profissão e o grau de instrução da mãe ofereceram potencial de explicação da formação dos grupos em $67 \%$ e $39 \%$, respectivamente, tal como se confirma pelo nível de significância e pela média de respostas de cada grupo. A análise dessas duas variáveis em conjunto demonstra que há uma reciprocidade entre o desempenho da profissão e o nível de instrução dessas mães, acentuando o distanciamento desses grupos por influência socioeducacional de suas mães.

A profissão e o grau de instrução do pai ofereceram potencial de explicação na formação dos grupos de $43 \%$ e 36\%, respectivamente, tal como se confirma pelo nível de significância e pela média de respostas de cada grupo. Também possui poder de distanciamento socioeducacional desses dois grupos, mesmo em menor intensidade, demonstra que pais com maior instrução conquistam as melhores posições na escala hierárquica de ocupações atualmente. 
Tabela 1

Resumo do teste $\chi^{2}$ para as variáveis do perfil socioeducacional

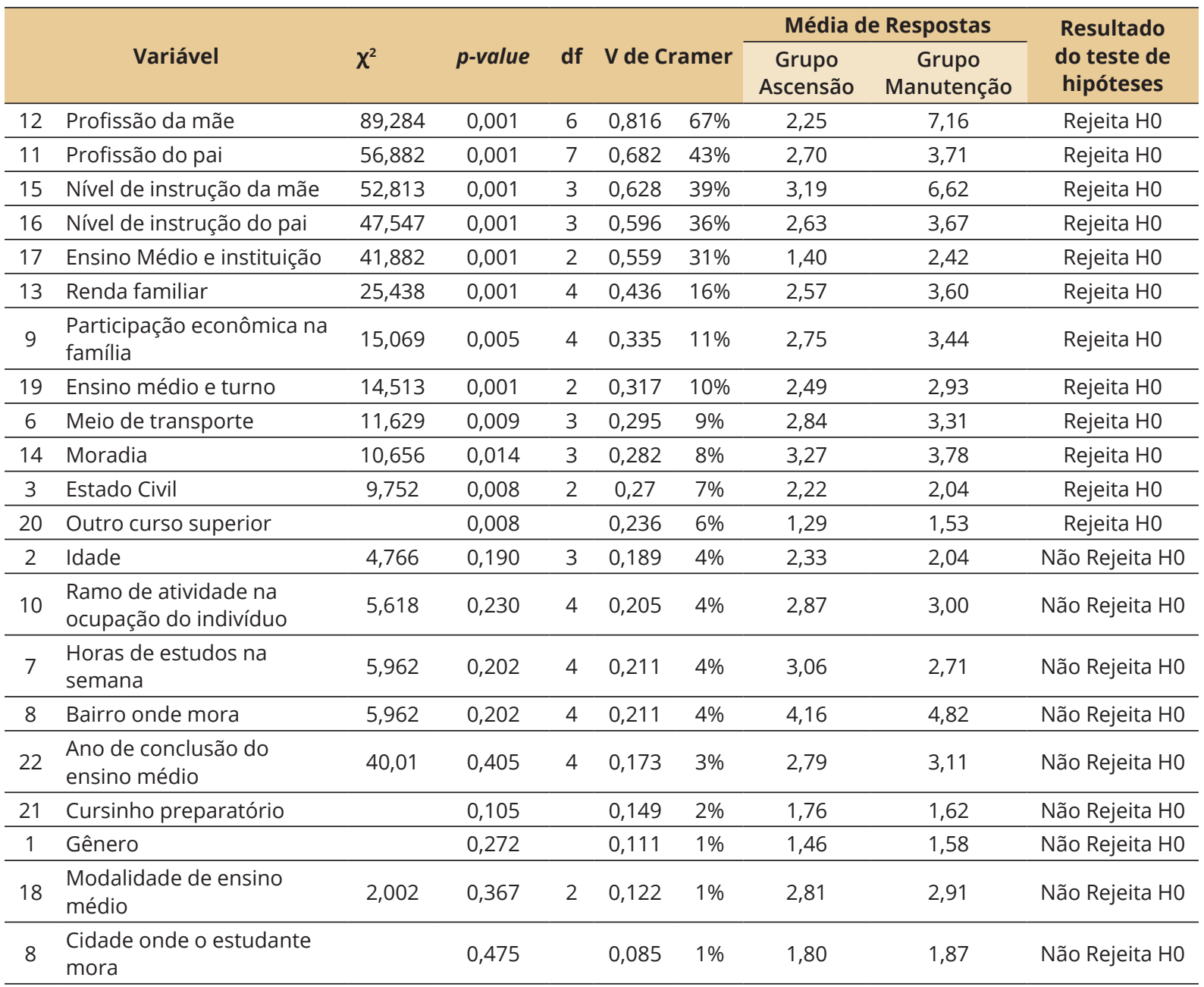

Fonte: Dados da pesquisa (2010).

Quanto ao ensino médio e insituição, a variável explicou a formação dos grupos na ordem de $31 \%$, tal como se confirma pelo nível de significância e média de respostas de cada grupo. Essa variável aponta que os estudantes do Grupo Ascensão frequentaram escolas públicas de forma integral ou parcial durante os anos de ensino médio e os estudantes do Grupo Manutenção frequentaram escolas particulares de forma integral ou parcial durante os anos de ensino médio. A modalidade de ensino público ou privado entre os dois grupos admite estratos de renda distintos entre eles.

A variável renda familiar, com poder de explicação dos grupos na ordem de $16 \%$, distingue o poder econômico entre eles, trazendo algumas pesadas consequências para cada um dos membros dos grupos, tais como a limitação de realização de alguns desejos futuros. O Grupo Ascensão atualmente mais sente as restrições advindas da sua escassa renda e de seus familiares.

A variável participação econômica na família e o turno em que fez o ensino médio ofereceram potencial de explicação da formação dos grupos de $11 \%$ e 10\%, respectivamente. Essas variáveis, juntas analisadas, evidenciam que estudantes do Grupo Ascensão desenvolveram atividades remuneradas durante o dia e estudaram durante a noite, em função da necessidade de participação na renda da família.

As variáveis meio de transporte até a universidade e moradia ofereceram potencial de explicação da formação dos grupos de $9 \%$ e $8 \%$, respectivamente. A moradia em residência própria, característica econômica distinta nos membros do Grupo Manutenção, evidencia, além da renda mais elevada, possibilidade de investimentos em outros bens de valores e de consumo, tal como se observa a possibilidade 
de locomoção por meio de veículo próprio - moto ou carro - posição diferente da do Grupo Ascensão, dependente de residência alugada e de terceiros, e utilização de transporte público para sua locomoção.

O estado civil de cada um dos membros explicou 7\% do potencial de formação dos grupos e constata-se maior número de casados nos membros do Grupo Ascensão. Essa variável, se analisada em conjunto com as demais anteriormente, pode explicar parte das dificuldades enfrentadas atualmente pelos membros do grupo. Além do compromisso de estudar à noite e trabalhar durante o dia, a maioria deles dividem a preocupação de si mesmo com pessoas totalmente dependentes deles, tais como cônjuges e filhos.

Em partes, a condição civil de cada um dos membros dos grupos se explica pela idade atual dos respondentes. A variável idade apresentou poder de explicação na formação dos grupos na ordem de $6 \%$. Os membros do Grupo Ascensão estão posicionados nas faixas mais elevadas, predominando a média de idade entre 20 e 29 anos, diferentemente dos elementos do Grupo Manutenção, cuja média de idade foi de 19 anos.

As demais variáveis ofereceram potencial de explicação na formação dos grupos com menor amplitude, conforme as evidências estatísticas dos testes efetuados, sendo que algumas não apresentaram poder de influência nos grupos estudados nesta amostra.

\subsection{Análise da influência socioeducacional nas dificuldades percebidas}

Nesta sessão, faz-se a análise discriminante das dificuldades percebidas pelos estudantes pesquisados. Os pressupostos de normalidade e homogeneidade da variância para as dificuldades percebidas resultaram em um teste $M$ de Box com Sig. F igual a 0,705, que não permite afirmar que há significância das diferenças observadas, havendo igualdade das dispersões entre os grupos (Fávero, Belfiore, Silva, \& Chan, 2009). A Tabela 2 resume o procedimento stepwise, indicando quais variáveis foram adicionadas como discriminantes e o correspondente valor de $\Lambda$ de Wilks, que relata as variáveis com capacidade discriminante para as dificuldades percebidas.

Tabela 2

Variáveis discriminantes pelo procedimento Stepwise das dificuldades percebidas

\begin{tabular}{|c|c|c|c|c|c|c|c|c|c|}
\hline \multirow{3}{*}{ Step } & \multirow{3}{*}{ Entered } & \multicolumn{8}{|c|}{ Wilks' Lambda } \\
\hline & & \multirow{2}{*}{ Statistic } & \multirow{2}{*}{ df1 } & \multirow{2}{*}{$\mathrm{df} 2$} & \multirow{2}{*}{ df3 } & \multicolumn{4}{|c|}{ Exact $F$} \\
\hline & & & & & & Statistic & df1 & $\mathrm{df2}$ & Sig. \\
\hline 1 & $\begin{array}{l}\text { Q_II_20_Compreendo que a situação ideal é se } \\
\text { dedicar integralmente para o trabalho ou para o } \\
\text { estudo. }\end{array}$ & 0,931 & 1 & 1 & 132 & 9,790 & 1 & 132 & 0,002 \\
\hline 2 & $\begin{array}{l}\text { Q_II6_A falta de tempo para dormir e descansar } \\
\text { prejudica meu aprendizado. }\end{array}$ & 0,891 & 2 & 1 & 132 & 8,032 & 2 & 131 & 0,001 \\
\hline 3 & $\begin{array}{l}\text { Q_II_18_Em situações reais, minha tendência é } \\
\text { simplificar a utilização de conceitos (simplificar as } \\
\text { técnicas aprendidas). }\end{array}$ & 0,845 & 3 & 1 & 132 & 7,966 & 3 & 130 & 0,000 \\
\hline 4 & $\begin{array}{l}\text { Q_II_24_Sinto que precisa mais confiança entre } \\
\text { professor e estudante. }\end{array}$ & 0,818 & 4 & 1 & 132 & 7,165 & 4 & 129 & 0,000 \\
\hline 5 & $\begin{array}{l}\text { Q_II_22_Para mim, a explicação em sala de aula é, } \\
\text { em geral, muito técnica e de difícil compreensão. }\end{array}$ & 0,792 & 5 & 1 & 132 & 6,730 & 5 & 128 & 0,000 \\
\hline
\end{tabular}

Fonte: Dados da pesquisa (2010).

O resultado da tolerância para cada variável, em cada passo que discriminou as dificuldades percebidas, excluiu uma variável por vez, até que nenhuma apresentasse um Valor Sig. $F<0,05$. Foram executados 5 passos por meio da análise Stepwise.

A variância explicada em termos de diferença entre os grupos está representada na Tabela 3, onde o valor Engenvalues é uma medida que representa o quanto cada função é diferente na Função Discriminante. Quanto mais afastados de 1 forem os grupos, maiores serão as variações explicadas entre os grupos 
pela função discriminante (Fávero et al., 2009). O output apresentado pela função discriminante relata que contribui com $100 \%$ para demonstrar as diferenças entre os grupos.

Tabela 3

Eigenvalues relativos às dificuldades percebidas

\begin{tabular}{ccccc}
\hline Function & Eigenvalue & \% of Variance & Cumulative \% & Canonical Correlation \\
\hline 1 & 0,263 & 100 & 100 & 0,456 \\
\hline
\end{tabular}

Fonte: Dados da pesquisa (2010)

A Tabela 4 mostra a significância da função discriminante, por meio da qual se observa a diferença entre os grupos.

Tabela 4

Lambda de Wilks e $\chi^{2}$ para significância da função discriminante das dificuldades percebidas

\begin{tabular}{ccccc}
\hline Test of Function(s) & Wilks' Lambda & Chi-square & df & Sig. \\
\hline 1 & 0,792 & 30,225 & 5 & 0,000 \\
\hline
\end{tabular}

Fonte: Dados da pesquisa (2010).

Os valores dos coeficientes padronizados das funções discriminantes das dificuldades percebidas, na Tabela 5, podem ser utilizados para avaliar a importância de cada variável explicativa na função discriminante e posterior interpretação dos resultados.

Tabela 5

Coeficientes padronizados das funções discriminantes das dificuldades percebidas

\begin{tabular}{lc} 
& Function \\
\hline Q_II_6_A falta de tempo para dormir e descansar prejudica meu aprendizado. & 1,000 \\
\hline $\begin{array}{l}\text { Q_II_18_Em situações reais, minha tendência é simplificar a utilização de conceitos (simplificar as } \\
\text { técnicas aprendidas). }\end{array}$ & 0,452 \\
\hline Q_II_20_Compreendo que a situação ideal é se dedicar integralmente para o trabalho ou para o estudo. & $0,0,513$ \\
\hline Q_II_22_Para mim, a explicação em sala de aula é, em geral, muito técnica e de difícil compreensão. & 0,458 \\
\hline Q_II_24_Sinto que precisa mais confiança entre professor e estudante. & $-0,511$
\end{tabular}

Fonte: Dados da pesquisa (2010).

- A análise dos valores médios das variáveis discriminantes confirma diferentes dificuldades percebidas em cada passo quanto às variáveis destacadas na análise discriminante:

- na variável Q_II_6, que menciona a interferência no aprendizado por conta da falta de tempo para dormir e descansar, a concordância foi maior entre os indivíduos do Grupo Ascensão;

- na variável Q_III_18, que menciona a aplicação de conceitos aprendidos em situações reais, a concordância foi maior entre o Grupo Manutenção;

- na variável Q_III_20, que menciona a alternância de tempo dedicado ao estudo e trabalho, em que afirma ser necessária uma das opções, a concordância foi maior entre os indivíduos do Grupo Ascensão;

- na variável Q_II_22, que menciona a dificuldade de acompanhamento da explicação em sala de aula, em que o estudante julga o procedimento de explicação muito técnico, a concordância maior foi entre os indivíduos do Grupo Ascensão;

- na variável Q_II_24, que menciona a confiança entre professor e estudante, a concordância foi maior entre os indivíduos do Grupo Manutenção. 
De forma analítica, a Tabela 6 dispõe os valores médios das respostas nas variáveis discriminantes para cada grupo.

Tabela 6

Valores médios das variáveis discriminantes

\begin{tabular}{lcc}
\cline { 2 - 3 } & Ascensão & Manutenção \\
\hline Q_II_6_A falta de tempo para dormir e descansar prejudica meu aprendizado. & 4,64 & 3,93 \\
\hline $\begin{array}{l}\text { Q_II_1_Em situações reais, minha tendência é simplificar a utilização de conceitos } \\
\text { (simplificar as técnicas aprendidas). }\end{array}$ & 3,72 & 4,22 \\
\hline $\begin{array}{l}\text { Q_II_20_Compreendo que a situação ideal é se dedicar integralmente para o trabalho } \\
\text { ou para o estudo. }\end{array}$ & 3.78 & 2,87 \\
\hline $\begin{array}{l}\text { Q_II_22_Para mim, a explicação em sala de aula é, em geral, muito técnica e de difícil } \\
\text { compreensão. }\end{array}$ & 3,84 & 3,16 \\
\hline Q_II_24_Sinto que precisa mais confiança entre professor e estudante. & 3,93 & 4,16 \\
\hline
\end{tabular}

Fonte: Dados da pesquisa (2010).

Com base nas análises estatísticas das dificuldades percebidas, rejeita-se $\mathrm{H}_{1}$, porque os estudantes de Ciências Contábeis com diferentes perfis socioeducacionais diferenciam-se entre si quanto às dificuldades percebidas.

\subsection{Análise da Influência socioeducacional nas perspectivas profissionais}

Os pressupostos de normalidade e de homogeneidade da variância para as perspectivas profissionais resultaram em um teste $M$ de Box com Sig. $F$ igual a 0,092, o que não permite afirmar que há significância das diferenças observadas, havendo igualdade das dispersões entre os grupos (Fávero et al., 2009).

A Tabela 7 resume o procedimento stepwise, indicando quais variáveis foram adicionadas como discriminantes e o correspondente valor de $\Lambda$ de Wilks, que relata quais as variáveis adicionas minimizaram o valor de Lambda $(\Lambda)$. São as variáveis com maior capacidade discriminante para as perspectivas profissionais.

Tabela 7

Variáveis discriminantes pelo procedimento Stepwise das perspectivas profissionais

\begin{tabular}{|c|c|c|c|c|c|c|c|c|c|}
\hline \multirow{3}{*}{ Step } & \multirow{3}{*}{ Entered } & \multicolumn{8}{|c|}{ Wilks' Lambda } \\
\hline & & \multirow{2}{*}{ Statistic } & \multirow{2}{*}{ df1 } & \multirow{2}{*}{ df2 } & \multirow{2}{*}{ df3 } & \multicolumn{4}{|c|}{ Exact $F$} \\
\hline & & & & & & Statistic & df1 & df2 & Sig. \\
\hline 1 & $\begin{array}{l}\text { Q_III_11_Acho que a profissão de contador está } \\
\text { sujeita a um pesado conjunto de requisitos legais. }\end{array}$ & 0,928 & 1 & 1 & 132 & 10,300 & 1 & 132 & 0,002 \\
\hline 2 & $\begin{array}{l}\text { Q_III_13_A formação contábil me permitirá mais } \\
\text { rapidamente ocupar um cargo gerencial ou diretivo. }\end{array}$ & 0,875 & 2 & 1 & 132 & 9,335 & 2 & 131 & 0,000 \\
\hline 3 & $\begin{array}{l}\text { Q_III_12_Em minha opinião, a formação contábil é a } \\
\text { que proporciona melhores condições de inserção no } \\
\text { mercado de trabalho. }\end{array}$ & 0,790 & 3 & 1 & 132 & 11,521 & 3 & 130 & 0,000 \\
\hline 4 & $\begin{array}{l}\text { Q_III_21_Tenho habilidades verbais, de liderança, } \\
\text { interpessoais ou outras que me proporcionam } \\
\text { estabilidade e sucesso na profissão. }\end{array}$ & 0,761 & 4 & 1 & 132 & 10,108 & 4 & 129 & 0,000 \\
\hline 5 & $\begin{array}{l}\text { Q_III_9_A profissão de contador é a mais compatível } \\
\text { com a minha condição social. }\end{array}$ & 0,736 & 5 & 1 & 132 & 9,190 & 5 & 128 & 0,000 \\
\hline 6 & $\begin{array}{l}\text { Q_III_6_Em minha opinião, o salário entre gêneros } \\
\text { (M/F) é igual na profissão contábil. }\end{array}$ & 0,700 & 6 & 1 & 132 & 9,053 & 6 & 127 & 0,000 \\
\hline 7 & $\begin{array}{l}\text { Q_III_7_Acredito que a oferta de empregos na área de } \\
\text { Contabilidade é muito grande. }\end{array}$ & 0,676 & 7 & 1 & 132 & 8,609 & 7 & 126 & 0,000 \\
\hline
\end{tabular}

Fonte: Dados da pesquisa (2010). 
O método de análise utilizado para testar a tolerância para cada variável em cada passo que discriminou as perspectivas profissionais em que cada passo excluiu uma variável por vez, até que nenhuma apresentasse um Valor Sig. F menor do que 0,05, foi a análise Stepwise, e executaram-se 5 passos.

A variância explicada em termos de diferença entre os grupos está representada na Tabela 8 , em que o valor Engenvalues é uma medida que representa o quanto cada função é diferente na Função Discriminante. Quanto mais afastados de 1 forem os grupos, maiores serão as variações explicadas entre os grupos pela função discriminante (Fávero et al., 2009). O output da função discriminante relata que contribui com 100\% para demonstrar as diferenças entre os grupos nas perspectivas profissionais.

Tabela 8

Eigenvalues relativos às perspectivas profissionais

\begin{tabular}{ccccc} 
Function & Eigenvalue & \% of Variance & Cumulative \% & Canonical Correlation \\
\hline 1 & 0,478 & 100 & 100 & 0,569 \\
\hline
\end{tabular}

Fonte: Dados da pesquisa (2010).

A Tabela 9 indica a significância da função discriminante, por meio da qual se observa a diferença entre os grupos.

Tabela 9

Lambda de Wilks e $\chi^{2}$ para significância da função discriminante das perspectivas profissionais

\begin{tabular}{ccccc}
\hline Test of Function(s) & Wilks' Lambda & Chi-square & df & Sig. \\
\hline 1 & 0,676 & 50,226 & 7 & 0,000 \\
\hline
\end{tabular}

Fonte: Dados da pesquisa (2010).

Os valores dos coeficientes padronizados das funções discriminantes das perspectivas profissionais, na Tabela 10, são utilizados para avaliar a importância de cada variável explicativa e na interpretação dos resultados.

A análise dos valores médios das variáveis discriminantes confirma que cada grupo possui perspectivas profissionais diferentes quanto às variáveis destacadas na análise discriminante.

Tabela 10

Coeficientes padronizados das funções discriminantes das perspectivas profissionais

\begin{tabular}{lc} 
& Function \\
\cline { 2 - 2 } Q_III_6_Em minha opinião, os salários entre gêneros (M/F) são iguais na profissão contábil. & 1,000 \\
\hline Q_III_7_Acredito que a oferta de empregos na área de contabilidade é muito grande. & $-0,430$ \\
\hline Q_III_9_A profissão de contador é a mais compatível com a minha condição social. & 0,361 \\
\hline Q_III_11_Acho que a profissão de contador está sujeita a um pesado conjunto de requisitos legais. & 0,401 \\
\hline Q_III_12_Em minha opinião, a formação contábil é a que proporciona melhores condições de inserção & 0,317 \\
no mercado de trabalho. & 0,556 \\
\hline Q_III_13_A formação contábil me permitirá mais rapidamente ocupar um cargo gerencial ou diretivo. & $-0,627$ \\
\hline $\begin{array}{l}\text { Q_III_21_Tenho habilidades verbais, de liderança, interpessoais ou outras que me proporcionam } \\
\text { estabilidade e sucesso na profissão. }\end{array}$ & $-0,427$
\end{tabular}

Fonte: Dados da pesquisa (2010).

- na variável Q_III_6, que menciona a igualdade de salário na profissão contábil, a concordância é maior entre os indivíduos do Grupo Manutenção;

- na variável Q_III_7, que menciona a grande oferta de emprego na área contábil, a concordância é maior entre os indivíduos do Grupo Ascensão; 
- na variável Q_III_9, que menciona a compatibilidade da profissão de contador com a condição social do estudante, a concordância é maior entre os indivíduos do Grupo Ascensão;

- na variável Q_III_11, que menciona que a profissão contábil está sujeita a um conjunto de requisitos legais, a concordância é maior entre os indivíduos do Grupo Ascensão;

- na variável Q_III_12, que menciona condições de inserção no mercado de trabalho proporcionado pela formação contábil, a concordância é maior entre os indivíduos do Grupo Ascensão;

- na variável Q_III_13, que menciona o benefício de ascensão a cargos gerenciais e diretivos, proporcionado pela formação contábil, a concordância é maior entre os indivíduos do Grupo Manutenção;

- Na variável Q_III_21, que menciona habilidades verbais, de liderança, interpessoais ou outras que proporcionam estabilidade e sucesso na profissão, a concordância é maior entre os indivíduos do Grupo Manutenção.

De forma analítica, a Tabela 11 apresenta os valores médios das respostas nas variáveis discriminantes para cada grupo.

Tabela 11

Valores médios das variáveis discriminantes

\begin{tabular}{lcc} 
& Ascensão & Manutenção \\
\hline Q_III_6_Em minha opinião, os salários entre gêneros (M/F) são iguais na profissão contábil. & 3,44 & 3,89 \\
\hline Q_III_7_Acredito que a oferta de empregos na área de contabilidade é muito grande. & 5,06 & 4,58 \\
\hline Q_III_9_A profissão de contador é a mais compatível com a minha condição social. & 4,02 & 3,40 \\
\hline $\begin{array}{l}\text { Q_III_11_Acho que a profissão de contador está sujeita a um pesado conjunto de } \\
\text { requisitos legais. }\end{array}$ & 5,10 & 4,51 \\
\hline $\begin{array}{l}\text { Q_III_12_Em minha opinião, a formação contábil é a que proporciona melhores condições } \\
\text { de inserção no mercado de trabalho. }\end{array}$ & 4,36 & 3,84 \\
\hline $\begin{array}{l}\text { Q_III_13_A formação contábil me permitirá mais rapidamente ocupar um cargo gerencial } \\
\text { ou diretivo. }\end{array}$ & 3,72 & 4,27 \\
\hline $\begin{array}{l}\text { Q_III_21_Tenho habilidades verbais, de liderança, interpessoais ou outras que me } \\
\text { proporcionam estabilidade e sucesso na profissão. }\end{array}$ & 4,15 & 4,60
\end{tabular}

Fonte: Dados da pesquisa (2010).

Com base nas análises estatísticas das perspectivas profissionais, rejeita-se $\mathrm{H}_{2}$ porque os estudantes de Ciências Contábeis, com diferentes perfis socioeducacionais, diferenciam-se entre si quanto às perspectivas profissionais.

\section{Considerações finais}

O objetivo geral deste estudo foi identificar, por meio de evidências estatísticas, se os diferentes perfis socioeducacionais influenciam as dificuldades percebidas e as perspectivas profissionais dos estudantes de Ciências Contábeis da UFPR. Para alcançar este objetivo, o trabalho exigiu abrangência e profundidade no incremento metodológico que, seguindo um conjunto de procedimentos, comprovou a existência de dois grupos distintos entre si. No que tange aos objetivos específicos propostos, o estudo alcançou os resultados apresentados adiante.

O alcance do objetivo específico um se deu da seguinte forma: os perfis socioeducacionais dos estudantes, delineados a partir do questionário e do procedimento estatístico, confirmaram que os estudantes do curso de Ciências Contábeis da UFPR são provenientes de estratos desiguais da população, com perfis distintos, o que permitiu distribuí-los em dois grupos, denominados de Grupo Ascensão, com 89 indivíduos, e Grupo Manutenção, com 45 indivíduos. 
Confirmadas as evidências de dois grupos socioeducacionais de estudantes, a amostra comprova que o Grupo Ascensão situa-se em um estrato inferior das camadas sociais brasileiras, e o Grupo Manutenção encontra-se em estrato mais elevado. Estas sustentações, ancoradas na manifestação individual de cada estudante, pela significância estatística de cada variável na formação do seu grupo e na média de respostas do conjunto de estudantes de cada grupo, emergem na definição dos grupos - a ocupação dos pais e mães dos estudantes do Grupo Ascensão resultou em predominância de baixa relação com os níveis de conhecimento técnico e teórico, situando-se nas posições inferiores da escala ocupacional, como revelado na média das respostas. Resultado inverso evidencia as afirmações dos membros do Grupo Manutenção - a ocupação dos pais e mães desses estudantes situa-se em níveis mais elevados da escala ocupacional.

O alcance dos objetivos específicos dois e quatro se deu da seguinte maneira: as principais dificuldades percebidas pelos estudantes concentram-se com maior ênfase em um dos grupos. Além das variáveis discriminantes destacadas, a média de respostas em cada variável mostra que as maiores dificuldades dos estudantes pertencentes ao Grupo Ascensão dizem respeito ao tempo necessário para estudar, dedicar-se a atividades como o trabalho e a família, além de outros fatores que dificultam o aprendizado do conteúdo do curso, levando-os a crer que o excesso de conteúdo é inapropriado para suas perspectivas.

Para os estudantes do Grupo Manutenção, as dificuldades percebidas se manifestam na inserção como profissional no mercado de trabalho, tais como a falta de tempo para os estudos, os conteúdos relativamente técnicos e a desconfiança por parte dos estudantes de que estão aprendendo algo inadequado também contribui para distanciar estudantes desse grupo dos professores.

As variáveis que atenderam ao objetivo de compor o quadro das principais dificuldades permitiram testar, estatisticamente, as hipóteses da pesquisa e rejeitar $\mathrm{H}_{1}$, porque os estudantes de Ciências Contábeis com diferentes perfis socioeducacionais diferenciam-se entre si quanto às dificuldades percebidas.

O alcance dos objetivos específicos três e cinco se deu da seguinte maneira: além das variáveis destacadas pela análise discriminante para as perspectivas profissionais dos estudantes, os grupos se diferenciam quanto às perspectivas em termos de sua atuação como contador e de sua inserção no mercado de trabalho.

Os estudantes do Grupo Ascensão são os que mais compartilham a visão de que, na profissão contábil, não terão problemas no mercado de trabalho, devido à grande oferta de emprego, e a profissão como representação da condição social é mais aceita pelos estudantes desse grupo, status não tão esperado pelos estudantes do Grupo Manutenção. Tal fato se alia ao mercado de trabalho e à oferta de emprego na área. A condição social dos elementos de cada grupo nem sempre julgam estar adequadas à profissão de contador.

A profissão contábil é vista pelos dois grupos como um meio pelo qual podem se valer para ocupar funções de nível gerencial ou diretivo nas empresas, porém o grupo o Grupo Manutenção concorda mais com essa afirmação. Esse fato sugere que os indivíduos pertencentes a cada grupo têm ainda alguns valores individuais, necessitando ser revistos para permitir a continuidade do crescimento para níveis mais elevados das condições sociais destacadas no referencial teórico, tais como: renda, ocupação e nível de instrução dos elementos do grupo.

As variáveis que atenderam ao objetivo de compor o quadro das perspectivas profissionais foram suficientes para testar estatisticamente as hipóteses da pesquisa e rejeitar $\mathrm{H}_{2}$, porque os estudantes de Ciências Contábeis com diferentes perfis socioeducacionais diferenciam-se entre si quanto às perspectivas profissionais.

Como limitação do estudo, cabe citar que, na análise, foram contemplados 134 estudantes dos períodos intermediários $\left(2^{\circ}\right.$ e $3^{\circ}$ anos), restringindo-se assim os resultados a esta amostra. Pode-se considerar ainda como limitação o fato de ter sido pesquisada somente uma instituição de ensino para a coleta de dados.

\section{Referências}

Bomtempo, M. S. (2005). Análise dos fatores de influência na escolha pelo curso de graduação em administração: um estudo sobre as relações de causalidade através da modelagem de equações estruturais. Dissertação de Mestrado, Centro Universitário Álvares Penteado - UniFecap, São Paulo, SP, Brasil.

Cervo, A. L. \& Bervian, P. A. (2002). Metodologia Científica (5th Ed.) São Paulo: Prentince Hall. 
Cooper, D. R., \& Schindler, P. S. (2003). Métodos de Pesquisa em Administração (7a ed.). Porto Alegre: Bookman.

Escerdo, P. D., \& Quintana, A. C. (2007, outubro). Perfil do acadêmico que ingressa no curso de ciências contábeis na FURG. Revista do CRCRS, (4), 1-7.

Fávero, L. P., Belfiore, P., Silva, F. L. da, \& Chan, B. (2009). Análise de Dados - modelagem multivariada para tomada de decisões. Rio de Janeiro: Campus.

Ferreira, D. (2003). Manual de Sociologia (2a ed.). São Paulo: Atlas.

Giddens, A. (2005). Sociologia (4a ed.). Porto Alegre: Artmed.

Gil, A. C. (1996). Como Elaborar Projetos de Pesquisa (3a ed.). São Paulo: Atlas.

Guareschi, P. A. (1992). Sociologia da Prática Social. Petrópolis: Vozes.

Hair, J. F., Tatham, R. L., Anderson, R. E., \& Black, W. (2005). Análise Multivariada de Dados (5a ed.). Porto Alegre: Bookman.

Kurchaidt, S. M., Nascimento, I. R., Zanette, V. H., \& Camargo, L. K. P. (2008). Estudo do Desempenho Médio dos Alunos do Curso de Matemática no Vestibular de Primavera/2008 da UNICENTRO/ PR. Revista Ciências Exatas e Naturais, 10(1), 95-101.

Lagioia, U. C. T., Santiago, H. L. F., Gomes, R. B., \& Ribeiro, J. F., Filho. (2007). Uma investigação sobre as expectativas do estudantes e o seu grau de satisfação em relação ao curso de ciências contábeis. Revista Contemporânea de Contabilidade, 1(8), 121-138.

Leite, G. A., Filho. (2005). Atitudes e opiniões dos alunos do curso de graduação em ciências contábeis quanto a cursar pós-graduação: um estudo numa universidade pública. Anais do Encontro Nacional da Associação Nacional de Pós-Graduação e Pesquisa em Administração - EnANPAD. Brasília, DF, Brazil, 29.

Marion, J. C. (1999, Março). Uma visão panorâmica da profissão contábil. Revista do CRCPR, 8-9.

Oliveira, P. S. (1999). Introdução à sociologia (19a ed.). São Paulo: Ática.

Pastore, J. (1979). Desigualdade e mobilidade social no Brasil (T. A. Queiroz, ed.). São Paulo: EDUSP.

Peleias, I. R., Petrucci, V. B. C., Garcia, M. N., \& Silva, D. da. (2008). Pesquisa sobre a percepção dos alunos $1^{\circ}$. ano de ciências contábeis na cidade de São Paulo em relação às dificuldades por eles percebidas no período noturno. Revista Universo Contábil, 4(1), 81-94.

Pinheiro, R. G. (2008). Fatores de Escolha Pelo Curso de Ciências Contábeis - uma pesquisa com os graduandos na capital e grande São Paulo. Dissertação de Mestrado, Centro Universitário Álvares Penteado - UniFecap, São Paulo, SP, Brasil.

Rabello, O. (1979). Um estudo de estratificação social e de inconsistência de status do estudante universitário. Tese de Livre-Docência, Universidade Estadual de Campinas, Faculdade de Educação, Campinas, SP, Brasil.

Raupp, F. M., \& Beuren, I. M. (2008). Coleta, Análise e Interpretação dos Dados. In: I. M. Beuren (Coord.). Como Elaborar Trabalhos Monográficos em Contabilidade - teoria e prática (3a ed.). São Paulo: Atlas.

Rehfeldt, M. J. H. (2006). Mudanças no Perfil dos Vestibulandos da Univates: uma análise ao longo dos últimos seis anos. Monografia de Especialização, Centro Universitário Univates, Lajeado, RS.

Richardson, R. J. (2007). Pesquisa social: métodos e técnicas (3a ed.). São Paulo: Atlas.

Schleich, A. L. R. (2006). Integração na educação superior e satisfação acadêmica de estudantes ingressantes e concluintes. Dissertação de Mestrado, Universidade Estadual de Campinas, Faculdade de Educação, Campinas, SP, Brasil.

Stefanello, S. (2010). O processo de ensino-aprendizado de língua Estrangeira na educação básica. Dissertação de Mestrado, Universidad Autónoma de Asunción, Asunción, Paraguay.

Takakura, M. (1992, jun/dez.). Formação Profissional do Contabilista. Enfoque - Reflexão Contábil, 5(5). 